\title{
Modelling the Combined Heat and Power Plants with Steam Turbines in the Study of Energy Security Problems
}

\author{
Victoria PISKUNOVA ${ }^{1 *}$, Dmitry KRUPENEV ${ }^{2}$, Egor KRUPENEV ${ }^{3}$, Natalia PYATKOVA ${ }^{4}$ \\ ${ }^{1-4}$ Melentiev Energy Systems Institute of Siberian Branch of the Russian Academy of Sciences, Irkutsk, \\ Lermontov Str., 130, Russian Federation \\ ${ }^{1-3}$ Irkutsk National Research Technical University, Irkutsk, Lermontov Str., 83, Russian Federation
}

\begin{abstract}
The paper considers the development of mathematical models of combined heat and power plants that are to be used while modelling the fuel and energy complex. Consideration is given to three methods of combined heat and power plant (CHP) modelling: The first method provides for the simplified modelling based on CHP aggregation in one energy zone; the second method is based on modelling the individual CHP using the accurate parameters of their equipment operation; the third method is based on the use of standard regime diagrams for modelling individual CHP. Analysis of the presented methods of CHP modelling revealed that the third method out of the three methods proposed is most appropriate for mathematical models of fuel and energy complex for studying the fuel and power supply reliability. The experimental part of the paper describes the process of deriving the analytical dependencies of electricity and heat generation versus fuel used by CHP that is obtained by the third method proposed.
\end{abstract}

Keywords - Combined heat and power plant (CHP); electric power engineering; energy security; fuel and energy system; heat power engineering; literature review; modelling; systems of nonlinear equations

\begin{tabular}{|lll|}
\hline \multicolumn{2}{|c|}{ Nomenclature } & \\
$Q_{0}$ & Heat to a turbine & $\mathrm{Gcal} / \mathrm{h}$ \\
$Q_{0}$ & Heat to a turbine in t.c.e. & cell \\
$Q_{p}$ & Heat to industrial needs & $\mathrm{Gcal} / \mathrm{h}$ \\
$Q_{t}$ & Heat to district heating & $\mathrm{Gcal} / \mathrm{h}$ \\
$Q_{k}$ & Heat to a condenser & $\mathrm{Gcal} / \mathrm{h}$ \\
$Q_{f}$ & Calorific value of conventional fuel & $\mathrm{Gcal} / \mathrm{h}$ \\
$D_{0}$ & Steam to a turbine & $\mathrm{t} / \mathrm{h}$ \\
$D_{t}$ & Steam to district heating & $\mathrm{t} / \mathrm{h}$ \\
$D_{k}$ & Steam to condensation & $\mathrm{t} / \mathrm{h}$ \\
$D_{p}$ & Steam to industrial needs & $\mathrm{t} / \mathrm{h}$ \\
$N$ & Power generation & $\mathrm{MW}$ \\
$N_{k}$ & Power generation due to steam release to a condenser & $\mathrm{MW}$ \\
\hline
\end{tabular}

* Corresponding author.

E-mail address: vitapiskunova98@gmail.com 


\begin{tabular}{|c|c|c|}
\hline$N_{(p, t)}$ & Forced power production depending on the heat consumption & MW \\
\hline$F$ & Fuel consumption & $\mathrm{t}$ \\
\hline$\lambda$ & Curve factor & - \\
\hline$\beta$ & Curve change $D_{p}$ & - \\
\hline$\Delta$ & Distance between curves $D_{p}=0$ and $D_{p}=20$ & cell \\
\hline$\eta_{M}{ }^{T}$ & Mechanical efficiency of a turbine (with account of friction losses) & - \\
\hline$\eta_{\mathrm{l}}$ & Generator efficiency & - \\
\hline$\eta_{\mathrm{b}}$ & Boiler efficiency & - \\
\hline$\eta_{1}$ & Relative internal efficiency of a high-pressure part of a turbine & - \\
\hline$\eta_{2}$ & Relative internal efficiency of a low-pressure part of a turbine & - \\
\hline$\eta_{3}$ & Relative internal efficiency of a feed pump & - \\
\hline$h_{1}$ & Live steam enthalpy & $\mathrm{kJ} \cdot \mathrm{mol}^{-1}$ \\
\hline$h_{1}^{\prime}$ & $\begin{array}{l}\text { Steam enthalpy at the end of isentropic expansion in the high-pressure } \\
\text { part of a turbine }\end{array}$ & $\mathrm{kJ} \cdot \mathrm{mol}^{-1}$ \\
\hline$h_{1 \mathrm{om}}$ & Steam enthalpy in the high-pressure cylinder (release) & $\mathrm{kJ} \cdot \mathrm{mol}^{-1}$ \\
\hline$h 1^{\prime}$ & $\begin{array}{l}\text { Steam enthalpy at the end of isentropic steam expansion in the low- } \\
\text { pressure part of a turbine }\end{array}$ & $\mathrm{kJ} \cdot \mathrm{mol}^{-1}$ \\
\hline$h_{2 \delta}$ & Steam enthalpy at the end of expansion in the low-pressure cylinder & $\mathrm{kJ} \cdot \mathrm{mol}^{-1}$ \\
\hline$h_{3}$ & Condensate enthalpy before the feed pump & $\mathrm{kJ} \cdot \mathrm{mol}^{-1}$ \\
\hline$h_{3}^{\prime}$ & $\begin{array}{l}\text { Steam enthalpy at the end of steam condensation in the turbine } \\
\text { condenser }\end{array}$ & $\mathrm{kJ} \cdot \mathrm{mol}^{-1}$ \\
\hline$h_{3} "$ & $\begin{array}{l}\text { Steam enthalpy at the end of condensation in the network water heater } \\
\text { (boiler) }\end{array}$ & $\mathrm{kJ} \cdot \mathrm{mol}^{-1}$ \\
\hline$h_{4}$ & $\begin{array}{l}\text { Steam enthalpy at the end of isentropic condensate compression in the } \\
\text { feed pump }\end{array}$ & $\mathrm{kJ} \cdot \mathrm{mol}^{-1}$ \\
\hline$h_{4 \delta}$ & Condensate enthalpy before the steam generator & $\mathrm{kJ} \cdot \mathrm{mol}^{-1}$ \\
\hline
\end{tabular}

\section{INTRODUCTION}

Energy security implies protection of citizens, society, state, and economy from the threat of failure to meet the energy demand for economically feasible energy resources of acceptable quality, and from threat of energy supply interruption [1], [2]. Actually, it means balancing the demand for and supply of different types of fuel and energy in the face of different threats that have an impact on the fuel and energy complex, and, thus, result in supply reduction [3].

Methods for assessing the energy security levels can be conventionally divided into three groups: an indicator-based method, a method for modelling the interrelated operation of energy systems within a fuel and energy complex (FEC), and a combined method. Studies conducted consider problems of FEC modelling, a sub problem of combined heat and power (CHP) modelling, in particular.

FEC of the country is one of the largest and most noticeable inter-industry complexes that includes such formally independent industries as power engineering, heat engineering, coal and oil production industries, oil refining and gas industries, municipal utilities of cities and rural areas that are united technologically and spatially [4]-[6]. Present-day FEC structure is 
assumed to include renewable energy, cryoenergy, and a water supply economy that can be added to FEC or considered independently.

Objective of this study is development of mathematical models of relationship between electric energy, heat energy and fuel supply systems within CHP operation for their further use in the FEC model intended for studying the reliability of fuel and energy supply of consumers. The criterion for assessing energy security is to determine the shortage of fuel and energy in the implementation of threats to energy security. For this, it is necessary to accurately represent the energetic processes occurring in energy systems. The article only touches on the issues of modelling CHP in the study of energy security, although the task of studying energy security is much broader and, ultimately, in the study of energy security, all the elements that make up the energy system are modelled. The paper consists of the following sections: literature review includes review of methods for modelling the interrelated operation of electric, heat and fuel systems; a section devoted to methods of modelling presents the approaches to modelling the interrelated operation of FEC; the section of experimental studies gives examples of implementing the proposed approaches of CHP modelling with account of peculiarities of operation of electric power systems; conclusion offers the summary of the work done.

\section{LiteratURE REVIEW}

The study primarily focuses on the review and analysis of mathematical models of CHP that are applied in mathematical models of FEC for determination of energy resources shortage and undersupply; it is also advisable to consider mathematical models applied for optimization of other parameters of energy systems operation. It can be concluded that interrelated operation of electric, heat and fuel systems is mainly described by two main methods: by forming a multi-energy system (MES) or by direct modelling of CHP individually. The first method is described in [7]-[12]. Fuel systems in those papers are mainly presented by gas; coal, oil products and biofuel are, as a rule, not presented in MES description. Account of energy storage, cryoenergy and renewable energy is, undoubtedly, an advantage of those papers. All the papers presented selected an economic target function: minimization of fuel costs and expenditures; maximization of operating benefits, etc. Modelling the relationship between heat, electric energy and fuel is mainly presented as conversion of some energy form into the other one: gas boilers, boilers. Heat energy is also generated in the heat-recovery boilers installed after the gas turbine, which implies dependence of heat energy generation on the electric energy. The papers reviewed did not present the relationship mentioned. The analysis allows us to conclude that the third method for modelling the interrelation of energy flows can further be applied only for long-term forecasting of shortage-free energy supply in the islanded energy systems. It is conditioned by the fact that models discussed in this section cannot be applied to large energy systems as they cannot take into account peculiarities of all the processes and relationships in them.

The second method for describing the relations between electric energy, heat and fuel systems is described in [13]-[24]. Gravelsins et al. [13] address the flexibility issue by analysing the possibility of sector interconnection through power-to-heat and power-to-gas applications using a system dynamics approach. Chamandoust et al. [14] implement the simulation of the objective function based on mixed integral linear programs (MILP), which minimizes the operational costs of resources and electricity purchased from the network in terms of Real-Time Price (RTP). Koch et al. [15] developed a simulation model of district heating implemented in MATLAB that includes a gas-fired (natural or wood gas) CHP, a peak boiler and a heat storage device. Lai et al. [16] study technology of heat energy 
decoupling as one of the methods for enhancing the CHP efficiency. For that purpose, the authors modelled a coal-fired CHP with a reservoir for thermocline storage and optimized the system operation. Liu et al. [17] modelled a coal-fired CHP with a device for electric energy conversion into heat (an electric boiler or a heat pump), which ensures higher control range of CHP capacity. Qian et al. [18] analyses operation of present-day steam turbines based on the ideas put forward by Horlok [22] in 1987. The analysis consists in forecasting the CHP operation for optimum planning. Santos et al. [19] developed a mini-CHP fuelled by biomass with application of Rankine organic cycle technology [20]. For raising the efficiency, the authors modified a boiler in order to use energy contained in biomass combustion gases. Wang et al. [21] modelled a biogas-fired CHP on the solid oxide fuel cell. Authors performed a detailed modelling of the system from the level of electrode to the level of a package and a system.

Analysis of this block of papers shows that a larger variety of fuel is used for CHP modelling than in the first variant. But in the majority of studies CHP is modelled separately from the energy system. In the present study it is of importance to model CHP not only as an energy source, but, rather, as a converter of fuel into heat and electric energy. Furthermore, only one paper out of all the overviewed ones discusses the use of different fuel types at a power plant. In the conditions of an actual energy system, CHP shall always have a backup fuel source, for example, crude oil. This package of papers presents economic target functions only.

Melentiev Energy Systems Institute SB RAS has been dealing with the issues of energy security for a rather long time and developing special mathematical models both of energy systems, and of FEC as a whole [6], [23]-[25]. An initial version of a model called 'FEC Reliability' [23] presents four interrelated FEC systems: gas supply, coal supply, oil products supply systems, and power engineering. In the 'power engineering' sub model all the considered power plants are divided into three types: Thermal Power Plants (TPP), Hydro Power Plants (HPP), and Nuclear Power Plants (NPP). An energy resource is presented by electric energy (MWh) that does not allow account of system's specific features in full and construction of power consumption curves. Heat power engineering is additionally presented by a block of boiler houses. Depending on the type of the main fuel, TPPs are divided into coal-fired, crude oil-fired, those fired by gas and crude oil, power plants fired by local fuels (peat, shale), and by secondary energy resources. But that model lacked relationship between heat and power engineering. 'FEC Reliability' model was modified into 'Reserv' model [24] and further in 'Reserv 2' model [5] that included fuel reserves and capacity backup. Furthermore, as a result of modification, TPPs in the model were divided into Condensing Power Plants (CPPs) and Combined Heat and Power (CHP) plants that allowed account of relationship between heat and electric power that expressed itself in boundary regimes of CHP operation: heat-extraction and condensing modes. Let us discuss it in greater detail. After the subsequent modification, the model was renamed into 'FEC Development Model' [25]. As of today, this is the latest modification of the model. Relationship between heat and electric power systems in CHP is represented as power production versus heating load factor that ranges from 1 to 4 . The factor was determined based on statistical data of annual heat and power production by different CHP. This method of modelling gives only approximate reflection of real processes and does not provide high accuracy of calculations.

In [26] the authors propose a multi-parameter model of FEC operation at different operating modes, the main objective of the model being FEC control during large-scale disturbances. The paper takes into account the option of applying different types of fuel at one power plant, but it does not take into account heat energy. TPP in this paper is not divided into CPP and CHP. For this reason, let us consider the way the authors model TPP from the power 
engineering standpoint. A power plant in this work is presented as a node for fuel conversion into electric energy. Conversion is modelled using linear equations, constraints are set as inequalities.

The existing FEC models for planning the shortage-free energy supply and estimation of the energy security level are obsolete in terms of methodology. With view of the present-day development of energy systems, computers and mathematical apparatus, there is a need to upgrade the available or to develop new FEC models for more accurate and qualitative calculations.

The overview made allows us to conclude that the main objectives of the research conducted is selection of the optimum approach to CHP modelling with account of energy systems peculiarities and understanding the relationship between heat/electric energy systems, and a fuel supply system.

\section{Modelling APPROACHeS}

CHP is characterized by two modes of operation: condensing and heat extraction (for district heating) ones. Heat extraction mode with independent electricity production can also be considered as a separate mode. Electric power production in the heat extraction mode directly depends on the heat extraction load. For attaining the maximum efficiency, the plants maintain steam release at a maximum allowable level $(5-10 \%$ from the maximum possible release). Under emergency in the electric energy system the main task is to minimize power shortage, and, therefore, CHP is changed over to heat extraction mode with independent electricity production. Electricity production in this mode increases in direct proportion to increased steam release to a condenser.

Selection of approach to CHP modelling is an important stage in constructing the final model as this type of a plant is the most complicated one due to availability of three (and more, fuel variety being considered) energy carriers. Calculation of ' $\mathrm{CHP}$ ' node shall not be excessively detailed and at the same time it shall demonstrate sufficiently high accuracy in order to make the results of modelling more certain.

It should be emphasized that present-day energy systems include a large number of components, which imposes constraints on the degree of studying each component as the final model shall not be overloaded to facilitate particular calculations and further engineering analysis [27].

Taking into account the above, the following criteria for assessing the applicability of the models were adopted:

- High accuracy of displaying technological processes;

- The optimal amount of input data required for modelling;

- Lack of unnecessary detail.

\subsection{Aggregated CHP for Energy Zones}

This approach consists in aggregating all the CHP at the selected energy area (an area, a city, a region) by averaging their characteristics. Similar approach was used in the existing models developed by Melentiev Energy Systems Institute SB RAS [6], [23]-[25]. It is based on modelling the aggregated dependencies of two types:

1. Fuel consumption vs heat production;

2. Electricity production versus heat extraction load. This method is the simplest among all the considered methods, but it is less accurate.

It implies search for aggregated dependencies applied at all CHP of the energy system. 
The first characteristic belongs to a boiler unit and is determined by its rated values given in its specification. Its general view is given in Fig. 1(a). In calculations the method of piecewise linear approximation was used in order to consider the forms of characteristics (Fig. 1(b)).

Fig. 1 shows that fuel consumption in the boiler depends on the amount of heat forwarded to a steam turbine. Heat in the turbine is consumed for electricity production and for heat extraction, accordingly, which can be presented as follows (Eq. (1)):

$$
Q_{0}=Q_{p}+Q_{t}+Q_{k},
$$

where $Q_{p}, Q_{t}, Q_{k}$ is the amount of heat supplied to industrial needs, to heat extraction and to heat supplied to a condenser, respectively.
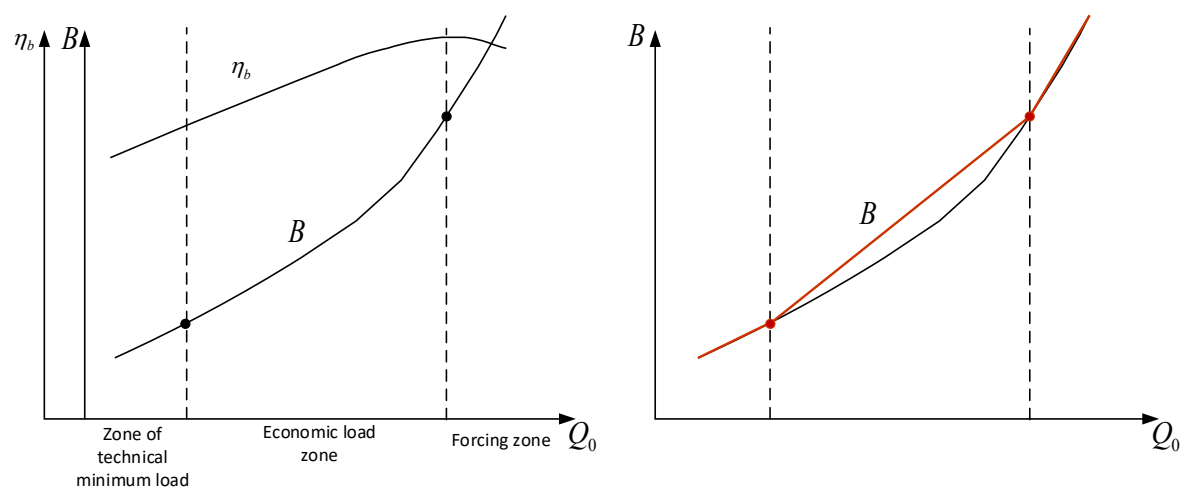

Fig. 1. General view of CHP boiler fuel consumption characteristic: a) Consumed; b) Approximated.

The amount of heat forwarded to a condenser depends on the CHP operating conditions. In the condensing mode there is no heat extraction, therefore, it is a function of power generated:

$$
Q_{k}=f(N)
$$

In the heat extraction mode, it is constant and equals $5-10 \%$ of the maximum possible discharge. In the heat extraction mode with independent electricity production, it equals:

$$
Q_{k}=f\left(N_{k}\right),
$$

where $N_{k}$ is amount of electricity produced at the expense of steam release to a condenser. It is determined by the formula:

$$
N_{k}=N-N_{(p, t)},
$$

where $N_{(p, t)}$ is forced power production depending on the heat extraction $N_{(p, t)}=f\left(Q_{(p, t)}\right)$.

This approach needs much time for the initial preparation, however, that is why the final program is the most "facilitated". The main disadvantage of the approach is its lowest accuracy. It suits best the calculation for the long-term planning of operating conditions. To make this type of calculation more accurate, one can model aggregate characteristics for each CHP individually. Simplification of the final program is also a positive feature. However, the accuracy in this case will be sufficient for the short-term evaluation of energy 
system capability to operate without energy shortage. Thus, this method does not meet the criterion of 'high accuracy of displaying technological processes'.

\subsection{Modelling of Individual CHPs Based on the Accurate Parameters of Equipment Operation}

This section presents an interpretation of the classical calculation of the cogeneration cycle of the steam turbine with one controlled steam extraction. This calculation is applied to construct a diagram of the cogeneration turbine modes. A steam turbine is the main element of the energy facility of the cogeneration cycle. The fuel consumption $F$ of the turbine is calculated by Eq. (5) [28]:

$$
F=\frac{D_{0} \cdot\left(h_{1}-h_{4 d}\right)}{\eta_{\mathrm{b}} \cdot Q_{f}} \mathrm{~kg} / \mathrm{h},
$$

where

$h_{I} \quad$ Enthalpy of the live steam;

$h_{4 \delta} \quad$ Enthalpy of the condensate before the steam generator;

$\eta_{\mathrm{b}} \quad$ Efficiency of the boiler unit;

$Q_{f} \quad$ Thermal value of fuel equivalent;

$D_{0} \quad$ Steam flow rate of the turbine and is determined by the Eq. (6):

$$
D_{0}=D_{k}+D_{t} \text {, }
$$

where

$D_{t} \quad$ Steam extraction corresponding to the thermal load;

$D_{k} \quad$ Quantity of steam for condensation. In case of the cogeneration mode, it is constant and equal to $5-10 \%$ of the maximum possible dumping. In the cogeneration mode with an independent power production.

$D_{k}$ is determined by Eq. (7) [29]:

$$
D_{k}=\frac{\frac{3600 \cdot N}{\eta_{M}^{T} \cdot \eta_{2}}-D_{t} \cdot H_{\partial}^{\prime}}{H_{\partial}},
$$

where

$\eta_{M}^{T} \quad$ Mechanical efficiency of the turbine (considering the losses due to traction);

$\eta_{\mathrm{L}} \quad$ Generator efficiency;

$H_{\delta} \quad$ Real difference of steam enthalpy in the turbine $\left(H_{\delta}=h_{1}-h_{2 \mathrm{D}}\right)$;

$h_{2 \mathrm{D}} \quad$ Steam enthalpy in the end of the expansion process in the low-pressure cylinder;

$H_{\delta} \quad$ Real difference of steam enthalpy in the high-pressure cylinder (in the extraction) $\left(H_{\delta}=h_{1}-h_{1 \mathrm{ex}}\right)$;

$h_{1 \mathrm{ex}} \quad$ steam enthalpy in the high-pressure cylinder (in the extraction).

The key problem of this approach is to determine enthalpies. All the applied formulas are compiled in Table 1.

In Table $1, h_{1}{ }^{\prime}$ is the steam enthalpy at the end of the isotropic steam expansion in the highpressure turbine section, $h_{2}{ }^{\prime}$ is the steam enthalpy at the end of the isotropic steam expansion in the low-pressure turbine section, $h_{3}$ is the condensate enthalpy before the feed pump, $h_{3}{ }^{\prime}$ is the steam enthalpy at the end of the steam condensation process in the turbine condenser, $h_{3}{ }^{\prime}$ is the steam enthalpy at the end of the condensation process in the delivery water heater (boiler), $h_{4}$ is the steam enthalpy at the end of the isotropic condenser compression in the feed pump, $\eta_{1}$ is the relative internal efficiency of the high-pressure turbine section, $\eta_{2}$ is the 
relative internal efficiency of the low-pressure turbine section, $\dot{\eta}_{3}$ is the relative internal efficiency of the feed pump.

TABLE 1. CALCULATED FORMULAS FOR DETERMINATION OF ENTHALPIES

\begin{tabular}{lllll}
\hline $\boldsymbol{h}_{\mathbf{1}}$ & $\boldsymbol{h}_{\mathbf{1}}{ }^{\prime}$ & $\boldsymbol{h}_{\mathbf{1 e x}}$ & $\boldsymbol{h}_{\mathbf{2}^{\prime}}$ & $\boldsymbol{h}_{\mathbf{2}}$ \\
\hline by table* & by table* & $h_{1}-\left(h_{1}-h_{1}{ }^{\prime}\right) \cdot \eta_{1}$ & by table* & $h_{1}-\left(h_{1}-h_{1}{ }^{\prime}\right) \cdot \eta_{2}$ \\
\hline $\boldsymbol{h}_{\mathbf{3}}$ & $\boldsymbol{h}_{\mathbf{3}^{\prime}}$ & $\boldsymbol{h}_{\mathbf{3}}{ }^{\prime \prime}$ & $\boldsymbol{h}_{\mathbf{4}}$ & $\boldsymbol{h}_{\mathbf{4}}$ \\
\hline$\frac{D_{k} \cdot h_{3}^{\prime}+D_{t} \cdot h_{3}^{\prime \prime}}{D_{0}}$ & by table* & by table* & by table* & $h_{1}-\left(h_{1}-h_{1}{ }^{\prime}\right) \cdot \eta_{3}$ \\
\hline
\end{tabular}

* Tables 1-3 are taken from the manual [30].

The enthalpy values can be determined by the Tables on the basis of the known temperature and pressure of steam/condensate at a certain point of the operation cycle of CHP. This fact forms great difficulties in application of this approach to studies of the energy security, and fuel and energy supply to consumers.

This approach is the most accurate and detailed since it takes into consideration an energy carrier state in each stage of heat and power production. However, it does not allow the whole energy system to be modelled, as far as the final program will require too large computational capabilities. Therefore, for this approach, the criteria 'the optimal amount of input data required for modelling' and 'lack of unnecessary detail' are not met. It is more logical to apply a detailed calculation for modelling of individual parts of energy systems, in which a small amount of system elements makes it possible to consider each of them in greater detail.

\subsection{Modelling of Individual CHPs Based on Typical Diagrams}

Each turbine type has its own typical diagrams of operation, which can be used to determine $\mathrm{Q}_{0}, \mathrm{Gcal} / \mathrm{h}$, being the heat quantity supplied to the turbine, based on the known value of steam extractions (for the turbines of PT type), thermal and electric load. Subsequently fuel consumption in the boiler unit for production of $\mathrm{Q}_{0}$ is calculated by Eq. (8) [31]:

$$
F=\frac{3600 \cdot Q_{0}}{\eta_{\mathrm{b}} \cdot Q_{f}} \mathrm{~kg} / \mathrm{h} .
$$

However, in order to take into consideration, the typical diagram in further calculations, it must be approximated. The typical characteristics of each turbine have different forms, therefore they should be represented uniformly. After transformation, the equation will be of the following form:

$$
Q_{0}=f\left(N, D_{p}, D_{t}\right),
$$

where $D_{p}$ is the industrial steam extraction only for the turbines of PT type.

For some turbines (of T and R type) the relationships $Q_{0}=f(N)$ and $N=f\left(D_{t}\right)$ are specified, hence approximation is performed only for the turbines of PT type. The calculation algorithm is divided into several steps:

1. Introduction of a new variable $N^{\prime}$ to simplify the diagram approximation. It is a projection of the axis $D_{t}$ on the axis $N$ subject to the scale $m$. The scale is determined by the relation of division of the scale $N$ to division of the scale $D_{t}$;

2. If the lines $D_{p}$ are not parallel, and the distances among them change with the change of $N^{\prime}$, then the curvature of the line $D_{p}$ is taken into consideration as a function of changing $N^{\prime}$; 
3. Reduction of $Q_{0}$ to the standard form. It requires an individual step because the scale $Q_{0}$ in some diagrams is not uniform. It means that one cell of the diagram has no value in $\mathrm{Gcal} / \mathrm{h}$. The errors can be minimized by forming an array containing approximate values of the scale for different parts of the scale $Q_{0}$. In other diagrams $D_{0}$ is presented instead of the scale $Q_{0}$, and hence at this step the following formula is applicable:

$$
Q_{0}=\frac{D_{0} \cdot\left(h_{1}-h_{4 d}\right)}{3600} .
$$

Formation of the final equation that describes the operation mode of the turbine set at CHP. For this purpose, the relationship $Q_{0}=f\left(N^{\prime}\right)$, being a form of the curve $D_{p}=0$, is approximated by $15-$ 20 points with the help of the calculated module. Then the variable $D_{p}$ is added to the obtained relationship in terms of the scale and curvature of lines.

The visual presentation of approximation of the typical diagram is given in Section 4.

The suggested approach meets all the accepted criteria. It is also highly accurate but does not consider the level of micro-parameters. It needs detailed initial preparation consisting in approximation of the typical diagrams of all types of turbines. The final program will be much simpler than in the previous approach and requires fewer initial parameters.

If we analyse the presented models of CHP, then the most suitable for modelling the fuel and energy complex in modern conditions is the last of the presented models. This model accurately reflects the process of converting fuel into electricity and heat, and all the initial information is available for its practical implementation.

\section{Case Study}

The turbine PT-60-130/13, whose typical diagram is presented in [32], is taken as an example of approximation.

The typical diagram of the turbine of PT type is the most complex for approximation, as far as its final size depends on three variables: industrial steam extraction $D_{p}$, cogeneration steam extraction $D_{t}$ and power production $N$.

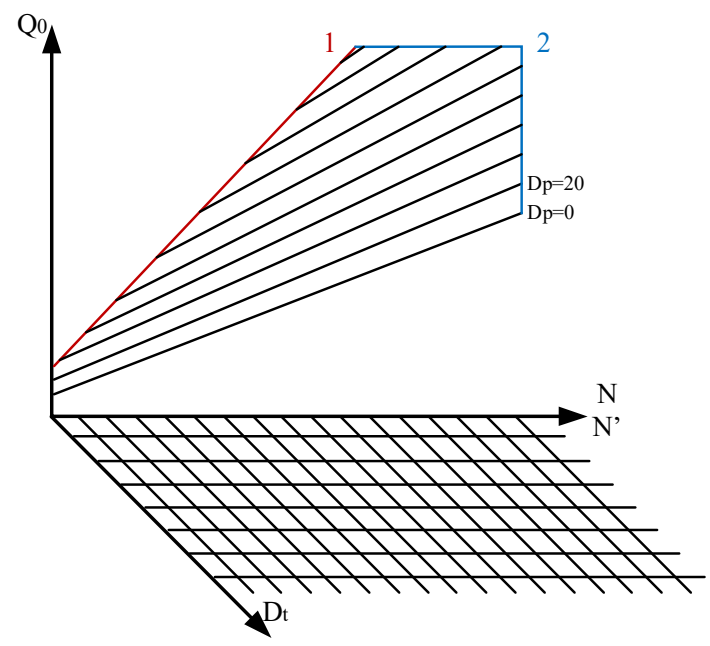

Fig. 2. A simplified form of the typical diagram. 
For better perception of the typical diagram presented in [29] it will be given in a simplified form. In Fig. 2 the red line 1 corresponds to steam escape from the medium-pressure turbine section that is equal to 20 tons per hour. The blue line 2 denotes limitations: the horizontal line limits the maximum allowed heat delivery, and the vertical one - the maximum power production.

At step $1, N$ and $D_{t}$ are expressed by one variable (Eq. (11)):

$$
N^{\prime}=N+m \cdot D_{t},
$$

where $m=0.1$ that is the dimensionless constant taking into consideration the plot scale.

At step 2, the curvature of the lines $D_{p}$ is considered as a function of the variable $N^{\prime}$. The uniform change of all lines allows one to consider only change of the curves $D_{p}=0$ and $D_{p}=20$. Determine the distances $\Delta$ between these curves on different sections of the plot in p.u. (in cells). The results are presented in Table 2.

TABle 2. Distances BetweEn the CuRves $D_{P}=0$ AND $D_{P}=20$

\begin{tabular}{llllll}
\hline $\boldsymbol{N}$ & $\mathbf{2}$ & $\mathbf{2 0}$ & $\mathbf{4 0}$ & $\mathbf{6 0}$ & $\mathbf{7 9}$ \\
\hline$D_{p}=0$ & 3.7 & 8.86 & 14.81 & 20.95 & 27.41 \\
$D_{p}=20$ & 4.8 & 10.14 & 16.26 & 22.58 & 29.21 \\
$\Delta$ & 1.1 & 1.28 & 1.45 & 1.63 & 18 \\
\hline
\end{tabular}

Table 2 shows that the value of $\Delta$ changes uniformly and proportionally to the value of $N^{\prime}$. Thus, the change of the curve $D_{p}$ as a function of $N^{\prime}$ is determined:

$$
\beta=\frac{\Delta_{1}-\Delta_{0}}{N_{1}^{\prime}-N_{0}^{\prime}}=\frac{1.8-1.1}{79-2}=0.009091
$$

Correspondingly, the curvature ratio will be equal to:

$$
\lambda=\Delta_{0}+\left(\left(N^{\prime}-2\right) \cdot \beta\right)=\Delta_{0}+\left(\left(N+m \cdot D_{t}-2\right) \cdot \beta\right) .
$$

$\left(N^{\prime}-2\right)$ is used to determine the initial point of the plot, as far as in Fig. 2 the plot starts with $N=2 \mathrm{MW}$.

At step 3, the scale $Q$ is determined. The array containing approximate values of the scale is formed for different sections of the scale $Q_{0}$ (Table 3 ). The subsequent calculation will be made in p.u. (in cells) with recalculation afterwards.

TABLE 3. The ARRAY of THE ScALE $Q_{0}$

\begin{tabular}{llllllllllll}
\hline $\boldsymbol{Q}_{\mathbf{0}^{\prime}}$ & $\mathbf{0 - 5}$ & $\mathbf{5 - 8}$ & $\mathbf{8 - 1 1}$ & $\mathbf{1 1 - 1 5}$ & $\mathbf{1 5 - 1 8}$ & $\mathbf{1 8 - 2 2}$ & $\mathbf{2 2 - 2 5}$ & $\mathbf{2 5 - 2 9}$ & $\mathbf{2 9 - 3 2}$ & $\mathbf{3 2 - 3 6}$ & $\mathbf{3 6 - 3 9}$ \\
\hline Scale & 6.67 & 6.45 & 6.32 & 6.15 & 6.06 & 6.03 & 5.96 & 5.88 & 5.83 & 5.8 & 5.77 \\
\hline
\end{tabular}

At step 4 the data of 15-20 points are put down into the program Wolfram Mathematica [33]. The program determines that the considered curve is the closest in form to the secondorder polynomial and can be described by the following expression:

$$
Q_{0}{ }^{\prime}=0.000378 \cdot N^{\prime 2}+0.275888 \cdot N^{\prime}+3.171708 .
$$

Then the formula is supplemented by the dependence on the variable $D_{p}$ and $N^{\prime}$ is identified as: 


$$
Q_{0}{ }^{\prime}=0.000378 \cdot\left(N+m \cdot D_{t}\right)^{2}+0.275888 \cdot\left(N+m \cdot D_{t}\right)+3.171708+\lambda \cdot \frac{D_{p}}{20} .
$$

The final relation between fuel, thermal and electric energy is derived:

$$
F=3600 \cdot \frac{0.000378 \cdot\left(N+m \cdot D_{t}\right)^{2}+0.275888 \cdot\left(N+m \cdot D_{t}\right)+3.171708+\lambda \cdot \frac{D_{p}}{20}}{\eta_{b} \cdot Q_{f}} .
$$

The calculated module, in which the daily fuel consumption was determined based on the load curves (Fig. 3(b)), was prepared using the given formulas. Considering a specific character of heat supply, it was assumed that the daily steam and heat extraction were constant and equal to $D_{t}=60 \mathrm{t} / \mathrm{h}$ and $D_{p}=80 \mathrm{t} / \mathrm{h}$, respectively. The plot of electricity consumption is presented in Fig. 3 a. In the calculations, $\eta=0.8$, and $Q_{f}=6000 \mathrm{Gcal} / \mathrm{h}$.
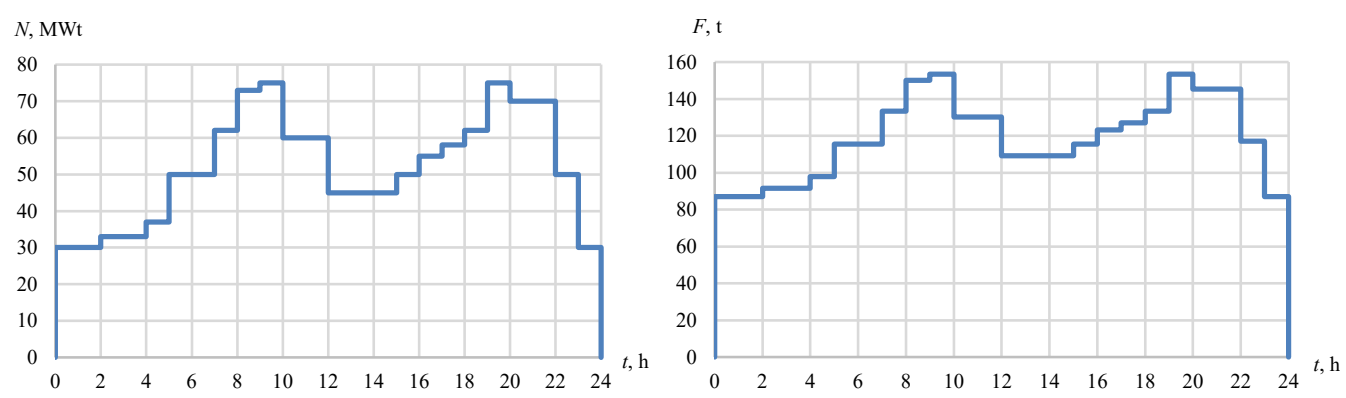

Fig. 3. The plots of the daily consumption of: a) electricity, b) fuel.

In the study performed an empiric dependence of fuel consumption in relation to the thermal and electric loads was revealed, the calculated module was written and tested. In the work, the thermal energy in the calculations was expressed by the steam quantity extracted from the turbines. In further studies, there are plans to convert thermal energy into $\mathrm{Gcal} / \mathrm{h}$, to set a system of constraints and to determine the forced power generation as a function of steam extractions.

\section{Conclusion}

The study of the problems of ensuring reliable fuel and energy supply is an integral part in planning the development of energy systems. This is, first of all, dictated by the high cost of energy equipment failure and the occurrence of damage to consumers due to the interruption of power supply. The paper considers the issue of mathematical modelling of CHPs for further use of the constructed models in FEC modelling. An analysis of the available literature on this issue revealed that the study is mainly aimed at solving particular economic problems in management of energy system operation.

The paper suggests three approaches to CHP modelling:

- The first approach provides for a simplified modelling based on the aggregation of a set of CHPs located in one energy zone. The main problem with this method is the low accuracy of the CHP representation. It is most applicable to calculation of long-term development planning, where low accuracy can be offset by an error in the forecasts. The positive factor of the approach is its relatively simple implementation;

- The second approach is based on modelling of individual CHPs on the basis of the 
accurate parameters of their equipment. This approach is the most accurate and detailed, as it takes into account the state of the energy carrier at each stage of heat and power production. In practice, the approach is difficult to apply to modelling of large energy systems when planning their expansion, since the detailed information needed on each generating unit is often unavailable for prospective schemes. It is more logical to apply such a calculation to modelling of decentralized energy systems, in which a small number of system components allow a more detailed consideration of each of them;

- The third approach is based on the use of typical diagrams of operating conditions for modelling of individual CHPs. This approach provides high accuracy but does not consider the level of micro-parameters of the units. However, in some cases, when there are no analytical dependences of the heat and power production on fuel consumption, significant initial preparation is required, which consists in approximation of typical turbine diagrams.

Calculations have shown good applicability of the proposed method for modelling combined heat and power plants for further implementation in a single model of the fuel and energy complex in the study of problems of reliability of fuel and power supply.

\section{ACKNOWLEDGMENT}

The research was carried out under State Assignment Project (no. FWEU-2021-0003) of the Fundamental Research Program of Russian Federation 2021-2030 and partly supported by the Russian Foundation of Basic Research, Grant No. 20-08-00367 using the resources of the High-Temperature Circuit Multi-Access Research Center (Ministry of Science and Higher Education of the Russian Federation, project no 13.CKP.21.0038).

\section{REFERENCES}

[1] Bushuyev V., Voropai N., Masterpanov A., Shafranik Yu. Energeticheskaja bezopasnostj Rossii (Energy security of Russia.). Moscow: 1998. (in Russian)

[2] Pyatkova N., Senderov S., Cheltsov M. Application of a two-level technology for research in solving energy security problems. Izvestiya RAN. Power Engineering 2000:6:31-39.

[3] Smirnova E., Senderov S. Energy security problems at the regional level: situation analysis and main trends. E3S Web Conferences 2019:77:01009 https://doi.org/10.1051/e3sconf/20197701009

[4] Voropai N. I. Sistemnie issledovanija v energetike. Retrospektiva nauchnih napravlenij (Energy Systems Institute schools of thought in hindsight.). Novosibirsk: Nauka, 2010. (in Russian)

[5] Belyaev L. S., et al. Metodi issledovanija i upravlenija sistemami energetiki (Methods of analysis and control of energy systems.). Novosibirsk: Nauka, 1987. (in Russian)

[6] Antonov G. N., et al. Metodi i modeli issledovanija zhivuchesti sistem energetiki (Methods and models for studying the survivability of energy systems.). Novosibirsk: Nauka, 1990. (in Russian)

[7] Yang S., et al. A two-stage optimization model for Park Integrated Energy System operation and benefit allocation considering the effect of Time-Of-Use energy price. Energy 2020:195:117013. https://doi.org/10.1016/j.energy.2020.117013

[8] Wu D., et al. Comparative study of optimization method and optimal operation strategy for multiscenario integrated energy system. Energy 2020:217:119311. https://doi.org/10.1016/j.energy.2020.119311.

[9] Luo F., et al. Research on optimal allocation strategy of multiple energy storage in regional integrated energy system based on operation benefit increment. International Journal of Electrical Power \& Energy Systems 2021:125:106376. https://doi.org/10.1016/j.ijepes.2020.106376

[10] Li P., et al. Hierarchically partitioned coordinated operation of distributed integrated energy system based on a masterslave game. Energy 2021:214:119006. https://doi.org/10.1016/j.energy.2020.119006

[11] Qin C., et al. Weighted directed graph based matrix modelling of integrated energy systems. Energy 2021:214:118886. https://doi.org/10.1016/j.energy.2020.118886.

[12] Chamandoust H., et al. Multi-objectives Optimal Scheduling in Smart Energy Hub System with Electrical and Thermal Responsive Loads. Environmental and Climate Technologies 2020:24(1):209-232. https://doi.org/10.2478/rtuect2020-0013

[13] Gravelsins A., et al. Power Sector Flexibility through Power-to-Heat and Power-to-Gas Application - System Dynamics Approach. Environmental and Climate Technologies 2019:23(3):319-332. https://doi.org/10.2478/rtuect2019-0098 
[14] Chamandoust H., Peyvand N. Energy Economic Management of Hybrid Energy System Based on Short-term Generation and Demand Response. Environmental and Climate Technologies 2020:24(1):653-668. https://doi.org/10.2478/rtuect-2020-0040

[15] Koch K., Höfner P., Gaderer M. Techno-economic system comparison of a wood gas and a natural gas CHP plant in flexible district heating with a dynamic simulation model. Energy 2020:202:117710. https://doi.org/10.1016/j.energy.2020.117710

[16] Lai F., et al. Operation optimization on the large-scale CHP station composed of multiple CHP units and a thermocline heat storage tank. Energy Conversion and Management 202:211:112767. https://doi.org/10.1016/j.enconman.2020.112767

[17] Liu M., Wang S., Yan J. Operation scheduling of a coal-fired CHP station integrated with power-to-heat devices with detail CHP unit models by particle swarm optimization algorithm. Energy 2021:214:119022. https://doi.org/10.1016/j.energy.2020.119022

[18] Qian Z., Agnew B. An assessment of Horlock's approximate analysis of feed and district heating cycles for steam and CHP plant. Thermal Science and Engineering Progress 2021:22:100746. https://doi.org/10.1016/j.tsep.2020.100746

[19] Santos M., et al. Design and modelling of a small scale biomass-fueled CHP system based on Rankine technology. Energy Procedia 2017:129:676-683. https://doi.org/10.1016/j.egypro.2017.09.143

[20] Baccioli A., et al. Potential energy recovery by integrating an ORC in a biogas plant. Applied Energy 2019:256:113960. https://doi.org/10.1016/j.apenergy.2019.113960

[21] Wang Y., et al. Analysis of a biogas-fed SOFC CHP system based on multi-scale hierarchical modelling. Renewable Energy 2021:163:78-87. https://doi.org/10.1016/j.renene.2020.08.091

[22] Horlock J. H. Approximate analyses of feed and district heating cycles for steam combined heat and power plant. Proceedings of the Institution of Mechanical Engineers 1987:201:A3. https://doi.org/10.1243\%2FPIME_PROC_1987_201_024_02

[23] Zorkaltsev V. I. Methods of forecasting and analysis of fuel supply system efficiency. Moscow: Nauka, 1988.

[24] Rudenko Yu. N. (ed.). Nadjozhnostj sistem energetiki i ih oborudovanija (Reliability of energy systems and their equipment.). Moscow: Energoatomizdat, 1994. (in Russian)

[25] Beresneva N. M., Pyatkova N. I. Features of Critical Facilities Determining for the Fuel and Energy Complex in Research of Fuel and Energy Supply. E3S web of conferences 2020:209:06001. https://doi.org/10.1051/e3sconf/202020906001

[26] Kozlov M. V., A. et al. Upravlenie topivno-energeticheskoj sistemoj pri krupnomashtabnih povrezhdenijah. I. Setevaja modelj I programmnaja realizacija (The fuel and energy system control in the event of large-scale damages. I. A network model and its software implementation.). Izv. RAN. Teoriya i sistemy upravleniya, 2017:6:50-73. (in Russian)

[27] Belyaev L. S., Rudenko Yu. N. (ed.). Teoreticheskie osnovi sistemnih isledovanij v energetike (Theoretical foundations of energy systems research.). Novosibirsk: Nauka, 1986. (in Russian)

[28] Popyrin L. S., Samusev V. I., Epelyptein V. V. Avtomatizacija matematicheskogo modelirovanija teploenergeticheskih ustanovok (Automation of mathematical modelling of thermal power plants.). Moscow: Nauka, 1981. (in Russian)

[29] Vulman F. A., Koryagin A. V., Krivoshey M. Z. Matematicheskoe modelirovanie teplovih shem paroturbinnih ustanovok (Computer-based mathematical modelling of steam turbine plants cycles.). Moscow: Mashinostroienie, 1985. (in Russian)

[30] Rivkin S. L., Alexandrov A. A. Termodinamicheskie svojstva vodi i vodjanogo para: Spravochnik (Thermodynamic properties of water and water vapor: a handbook.). Moscow: Energoatomizdat, 1984. (in Russian)

[31] Grigorieva V. A., Zorina V. M. (ed.). Thermal and nuclear power plants: a handbook. Moscow: Energoatomizdat, 1989.

[32] RD 34.30.711 Tipovaja normativnaja harakteristika turboagregata PT-60-130/13 LMZ (Type performance standard of pt-60-130/13 lmz turbine unit.). Moscow: USSR Ministry of Energy, 1974. (in Russian)

[33] Wolfram Mathematica [Online]. [Accessed 12.03.2021]. Available https://www.wolfram.com/mathematica/ 